\title{
Alpheus Bingham
}

InnoCentive cofounder Alpheus Bingham is bringing scientists together online to solve R\&D challenges and succeeding where many others have failed.

Alpheus Bingham is an Internet matchmaker. Except he isn't helping others find their love soul mate: his e-business lines up research needs with those who think they can solve them. That's not a particularly new concept in R\&D, but what sets Bingham apart is his success in tapping into "a world where everyone is connected and always on."

The idea began at Indianapolis-based Eli Lilly as a way for the company to connect its own researchers online. Bingham and colleague Aaron Schacht defined the concept in the late 1990s, and when InnoCentive was established in 2001 as a wholly owned subsidiary, Bingham, who was vice president for e.Lilly at the time, was placed at the helm, with project leader Darren Carroll reporting to him. It was spun out as an independent entity in December 2005.

The business model requires that organizations pay to post research problems, which can be accessed by the site's registered scientists, who offer solutions. For example, there are currently companies seeking a biomarker for measuring the progression of Lou Gehrig's disease, a diagnostic test for tuberculosis and a keratin-dissolving compound. Each company posts what it is looking for-along with a deadline for a solution - and offers a reward to anyone who solves the challenge.

The challenges, often posted anonymously, are written to mask how solutions might be applied and thus protect trade secrets, says Bingham. If a registered user expresses interest in the initial question, he or she signs an electronic nondisclosure agreement to receive more information. It costs nothing for the registered researchers, called 'solvers', to participate, and they number about 120,000, with about 50\% from North America and Europe, 20\% from China, 15\% from Russia and 15\% from India, says InnoCentive CEO Dwayne Spradlin, who took over from Bingham in November 2006 (although Bingham remains on the board). About one-third of all problems posed are solved, typically within three months, says Spradlin, adding up so far to about 108 challenges resolved with total cash awards of about $\$ 1.5$ million.

A for-profit company generally pays $\$ 100,000$ a year for the option to post challenges, plus another $\$ 2,500$ to get them up. If the company ends up awarding a researcher, InnoCentive collects $25 \%$ as a finder's fee. The company, which received $\$ 9$ million in series $\mathrm{A}$ financing in 2006, should turn a profit in 2008, says Spradlin.

Perhaps the inspiration for InnoCentive's crowd-sourcing technique came from the family life of 53-year-old Bingham; he is the oldest of six children and has six children of his own. He was born in Patience, Utah, and his father, a school teacher, packed up and moved the family whenever he got restless. After five years in Utah, the family shifted around the farming area of Modesto, California, but Bingham went back to Utah for college; he attended Brigham Young University and majored in chemistry. Later, he returned to California for Stanford, where he received a PhD in organic chemistry. He then accepted a job offer from Lilly, where he stayed until 2006.

The idea behind InnoCentive met with some initial resistance at Lilly. "Some people thought it was rude that not all good pharma research takes place in central Indiana or northern New Jersey, for instance," says Glenn Cornett, a former colleague of Bingham's at Lilly and now CEO of Navitas Pharma in Palo Alto, California. The key to making the project succeed both inside Lilly and as a standalone business was marrying the crowd-sourcing concept to capturing the resulting intellectual property (IP), says Cornett-Bingham's idea. For example, if a 'solver' is awarded the cash for a solution, the IP is granted to the seeker. But IP stays with a solver if their solution is not chosen.

The success of InnoCentive also comes not just from striving to reach large numbers of people, but diverse ones, as well. "These researchers are not the usual suspects," says Henry Chesbrough, executive director of the Center for Open Innovation at Haas School of Business at the University of California at Berkeley and an advisory to InnoCentive. They include "retired executives, students who have not yet hit the radar or people in other fields."

Michael Leonard, an assistant professor of chemistry at Washington \& Jefferson College in Washington, Pennsylvania, first saw an ad for InnoCentive in a trade magazine. Intrigued, he began visiting the site monthly to scroll through challenges. Over several years he has tackled six problems and won one, collecting \$10,000 in 2005 for

InnoCentive's success
comes from marrying
the crowd-sourcing
concept to capturing
the resulting IP.

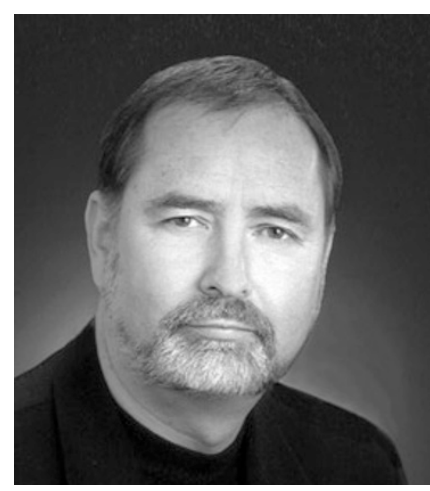

presenting a solution for why a preservative was degrading under certain $\mathrm{pH}$ conditions. Part of his award paid a summer research intern for his laboratory.

The largest amount of cash offered so far is $\$ 1$ million, by Prize4Life, a Cambridge, Massachusetts-based nonprofit focused on creating better treatments for amyotrophic lateral sclerosis (ALS). The million dollars is for a biomarker, but the organization has already awarded prizes for novel approach concepts to ALS research—getting its solutions from a group that included a dermatologist from Buffalo, New York, a post-doc chemistry researcher from the University of Iowa and a chemist from Italy.

Although there are similar companies in the space-NineSigma in Cleveland; yet2.com in Needham, Massachusetts; and YourEncore.com (Bingham is on the board) in Indianapolis-InnoCentive might have an advantage in that its founder considers himself different from the typical pharma veteran. In photos of executives in a Lilly online directory, "the executives are all in ties, [except] one man in a leather jacket," says Spradlin.

Bingham explains: "I discovered how to upload my own photo from when I rode across the country in 1990 on my Harley."

Ken Wilan, Westborough, Massachusetts 